\title{
Australian Trans and Gender Diverse (TGD) People and HIV/AIDS: A Discussion Paper
}

\author{
Belinda Chaplin* and Peta Harbour \\ College of Nursing \& Midwifery, Charles Darwin University, Northern Territory, Australia
}

\section{Article Info}

\author{
*Corresponding author: \\ Belinda Chaplin \\ College of Nursing \& Midwifery \\ Charles Darwin University \\ Northern Territory \\ Australia \\ Tel: +61429116700 \\ E-mail: belinda.chaplin@cdu.edu.au
}

Received: May 24, 2018

Accepted: May 30, 2018

Published: June 7, 2018

Citation: Chaplin B, Harbour P. Australian Trans and Gender Diverse (TGD) People and HIV/AIDS: A Discussion Paper. Madridge J AIDS. 2018; 2(1): 35-37.

doi: $10.18689 / \mathrm{mja}-1000106$

\section{Copyright: (c) 2018 The Author(s). This work is licensed under a Creative Commons Attribution 4.0 International License, which permits unrestricted use, distribution, and reproduction in any medium, provided the original work is properly cited.}

Published by Madridge Publishers

\begin{abstract}
We are now in the $21^{\text {st }}$ century where HIV is a treatable chronic condition through the use of antiretroviral therapies (ARTs). Yet, HIV remains an issue for minority populations who have been disproportionately and adversely affected by HIV even in first world countries such as Australia. There is no good reason for this. While TGD people may have access to such therapies as ART, the problem is not access to treatment, but recognition that they actually exist. This paper discusses the erasure of TGD people in the Australian h many levels [1], [8], [19]. In particular, is its perceived ealthcare system in the discourse around HIV, and concludes that their voices need to be heard.
\end{abstract}

Keywords: Trans and gender diverse; HIV.

Abbreviations: AIDS: Acquired Immunodeficiency Syndrome; ART: Antiretroviral Therapy; ASHM: Australian Society HIV Management; HIV: Human Immunodeficiency Virus; TGD: Trans and Gender Diverse; WHO: World Health Organisation.

\section{Main body}

Human immunodeficiency virus (HIV) is defined as a "blood-borne, sexually transmissible virus typically transmitted via sexual intercourse, shared intravenous drug paraphernalia, and mother to child transmission [1]. As the name implies, HIV attacks the immune system of its host and as the disease progresses, the host's immune system fails to respond to normally benign infections [1]. It is a treatable chronic condition, but if left untreated, is a precursor to AIDS, or acquired immunodeficiency syndrome [2]. In the late 1980s, life expectancy on being diagnosed with HIV was five years [3]. In a recent meta-analysis of HIV/AIDS survival rates, it was found that without treatment, "less than $50 \%$ of patients survive for 2 years after AIDS onset [4].

In a report by the World Health Organisation (WHO) [5], the continued upswing in the use of and improvement in antiretroviral therapy (ART) has meant a substantial reduction in the number of HIV infections (down 39\%) and HIV related deaths through AIDS (down $33 \%$ ) in the $21^{\text {st }}$ century. Consequently, the number of people living with HIV is increasing [6]. As of 2016, there are 36.7 million people living with HIV globally in 2016, of which 1.8 million were newly diagnosed. In the same period, one million people died from HIV-related causes [5]. From a local perspective in Australia, the latest figures are based upon the 2016 calendar year [7]. The Kirby Institute [7] reported that the number of people diagnosed with HIV in Australia since 1984 was estimated at 37,225, with 1013 newly diagnosed in 2016 (including 38\% of cases contracted overseas), with total deaths estimated at around 10000 since the early 1980s [8].

The WHO [9] identified several key populations who are "disproportionately affected by HIV" and underserved globally. These include people who inject drugs, sex workers, Men who have Sex with Men (MSM), incarcerated individuals, and trans and gender 
diverse (TGD) women [9]. According to WHO [9], TGD women "are 49 times more likely to be living with HIV than other adult females," and yet are largely ignored in the Oceanic region. In a report by UNAIDS [10], it was estimated that 19\% of TGD women live with HIV globally. There is little data available for TGD men. However, the literature that is available [11-13]. Indicates that TGD men are at similar risk of contracting HIV to that of TGD women due to risky sexual behaviours. While TGD women are noted as a key population by WHO [9], in the Australian context, they are not included as part of the Australian epidemic [14]. In effect, they are erased from the current discourse on HIV [15].

According to UNAIDS [15], no official data exists on TGD people from the Australian perspective. In Australia, the discourse around HIV continues to be concerned with MSM, heterosexual contact, MSM in combination with intravenous drug use, and intravenous drug use alone. Additionally, some discourse exists around Aboriginal and Torres Strait Islander peoples who are already included in the totals noted above [16]. This accounts for $96 \%$ of the total notifications in 2015. TGD people fall in the other $4 \%$ of notifications reported by The Kirby Institute [16], but they are not specifically categorised. The Australian Society HIV Management (ASHM) [14] also note TGD people as 'other' or 'undetermined'.

Contracting a condition such as HIV, while having significant ongoing medical implications for individuals including adhering to medication regimes [17], and the possibility of contracting opportunistic infections due to persistently low CD4 counts [1], also brings with it a level of public stigma [18] and possible or outright discrimination at many levels $[1,8,19]$. In particular, is its perceived association with casual sex and sexual promiscuity [1], mostly among the gay male community [20]. Furthermore, the stigma associated with living with HIV remains a barrier for long term positive health outcomes [21] for many patients. According to Vanable, Carey Blair and Littlewood [21], these barriers manifest themselves in "poor adherence, depressed mood, and decisions regarding serostatus disclosure." The stigma experienced through living with HIV may also be internalised $[18,22]$. This aspect could be particularly relevant to TGD people, who suffer from social [23] and internalised transphobia [24].

Returning to the Australian context, a clinical audit in one clinic in Sydney [25] reported high rates of HIV with 6/141 (4.25\%) TGD patients diagnosed with the condition; a finding consistent with that of The Kirby Institute [16]. Additionally, one Australian study, which reported on the health and wellbeing of TGD people in Australia and New Zealand [26], noted that the literature on HIV focused on its transmission. Although the numbers of new diagnoses of HIV in Australia remains relatively constant, according to the Australian Institute of Health and Welfare [27], HIV notifications per 100000 people have trended upwards since 2002 (from 4.4 to 5.7 per 100000). Therefore, HIV remains a significant chronic condition, and one in which the experiences of TGD people are ignored. The overwhelming majority of TGD related HIV literature is from an international context [28-30].

\section{Conclusion}

The prevalence of TGD people is estimated at $1.4 \%$ of the global population [31], yet are up to $4 \%$ of HIV notifications in Australia, which indicates a greater prevalence than the cisgender population. As a consequence, little attention is given to the needs of the TGD population in terms of HIV due to their erasure from the conversation. Furthermore, because there is a paucity of Australian literature in respect to the lived experience of TGD people with HIV, it is significantly relevant to understand the psychosocial aspects of TGD people living with HIV, and how they create meaning from their diagnosis. This can only raise greater awareness of the social problems faced by TGD people navigating life with the duel edged sword of being a TGD person living with a notifiable medical condition such as HIV. It is time to get the conversation started.

\section{Acknowledgements}

The authors wish to thank Professor Marilynne Kirshbaum, Nursing Discipline Leader in the College of Nursing \& Midwifery at Charles Darwin University for her support and guidance in the final draft of this paper.

\section{Conflict of Interest}

The authors confirm that there is no conflict of interest regarding this manuscript.

\section{References}

1. Bennett N. HIV infection and AIDS. 2017.

2. Rote $\mathrm{N}$, Huether $\mathrm{S}$, McCance $\mathrm{K}$. Hypersensitivities, infection, and immunodeficiencies. In: Huether S, McCance K, eds. Understanding pathophysiology. 2004; 181-220.

3. Pitts Mc. The Conversation. 2014; 25.

4. Poorolajal J, Hooshmand E, Mahjub H, Esmailnasab N, Jenabi E. Survival rate of AIDS disease and mortality in HIV-infected patients: a metaanalysis. Public Health. 2016; 139: 3-12. doi: 10.1016/j.puhe.2016.05.004

5. WHO. HIV/AIDS. 2017.

6. Boerner H. HIV rates drop across US, but especially in these states. 2017.

7. The Kirby Institute. HIV, viral hepatitis and sexually transmissible infections in Australia: Annual surveillance report 2017. 2017.

8. Power J. AIDS epidemic no longer a public health issue, but HIV still is. 2016

9. Serving the needs of key populations: Case examples of innovation and good practice in HIV prevention, diagnosis, treatment and care. 2017

10. UNAIDS. The gap report. 2014.

11. Kenagy GP, Hsieh CM. The risk less known: Female-to-male transgender persons' vulnerability to HIV infection. AIDS Care. 2005; 17(2): 195-207. doi: 10.1080/19540120512331325680

12. Rowniak S, Chesla C, Rose CD, Holzemer WL. Transmen: The HIV risk of gay identity. AIDS Education and Prevention. 2011; 23(6): 508-520. doi: 10.1521/aeap.2011.23.6.508

13. Stephens SC, Bernstein KT, Philip SS. Male to female and female to male transgender persons have different sexual risk behaviors yet similar rates of STDs and HIV. AIDS and Behavior. 2011; 15(3): 683-686. doi: 10.1007/ s10461-010-9773-1

14. Australian Society HIV Management. HIV management in Australia. 2016.

15. UNAIDS. AIDSinfo. 2016.

16. The Kirby Institute. HIV, viral hepatitis and sexually transmissible infections in Australia: Annual surveillance report 2016. 2016. 
17. Mannheimer SB, Matts J, Telzak E. Quality of life in HIV-infected individuals receiving antiretroviral therapy is related to adherence. AIDS Care. 2005; 17.

18. Corrigan PW, Watson AC. Understanding the impact of stigma on people with mental illness. World Psychiatry. 2002; 1(1): 16-20. doi: 10.1016/ S1077-7229(98)80006-0

19. Rongkavilit C, Wright $K$, Chen X, Naar-King S, Chuenyam T, Phanuphak $P$, et al. HIV stigma, disclosure and psychosocial distress among Thai youth living with HIV. International Journal of STD \& AIDS. 2010; 21(2): 126-132. doi: 10.1258/ijsa.2009.008488

20. Brener L, Wilson H, Slavin S, De Wit J. The impact of living with HIV: Differences in experiences of stigma for heterosexual and homosexual people living with HIV in Australia. Sexual Health. 2013; 10(4): 316-319. doi: $10.1071 / \mathrm{SH} 12170$

21. Vanable PA, Carey MP, Blair DC, Littlewood RA. Impact of HIV-related stigma on health behaviors and psychological adjustment among HIVpositive men and women. AIDS Behav. 2006; 10(5): 473-482. doi: 10.1007/ s10461-006-9099-1

22. Lee RS, Kochman A, Sikkema KJ. Internalized stigma among people living with HIV-AIDS. AIDS and Behavior. 2002; 6(4): 309-319.

23. Dean L, Meyer I, Robinson K, Sell R, Sember R, Silenzio V, et al. Lesbian, gay, bisexual, and transgender health: Findings and concerns. Journal of the Gay and Lesbian Medical Association. 2000; 4(3): 102-151.

24. Chaplin B. "Why are you crying? You got what you wanted!" Psychosocial experiences of sex reassignment surgery (Unpublished dissertation). Brisbane, Queensland, Queensland University of Technology 2016.
25. Pell C, Prone I, Vlahakis E. A clinical audit of male to female (MTF) transgender patients attending Taylor Square Private Clinic in Sydney, Australia, aiming to improve quality of care. The Journal of Sexual Medicine. 2011; 8 (3): 179.

26. Couch M, Pitts M, Mulcare H, Croy S, Mitchell A, Patel S. Tranznation: A report on the health and wellbeing of transgender people in Australia and New Zealand. 2007.

27. Australian Institute of Health \& Welfare. Australia's health 2016. 2016.

28. Rebchook G, Keatley J, Contreras R. The transgender women of color initiative: Implementing and evaluating innovative interventions to enhance engagement and retention in HIV care. American Journal of Public Health. 2017; 107(2): 224-229. doi: 10.2105/AJPH.2016.303582

29. Wiewel EW, Torian LV, Merchant P, Braunstein SL, Shepard CW. HIV diagnoses and care among transgender persons and comparison with men who have sex with men: New York City, 2006-2011. American Journal of Public Health. 2016; 106(3): 497-502. doi: 10.2105/AJPH.2015.302974

30. Lee SW, Deiss RG, Segura ER. A cross-sectional study of low HIV testing frequency and high-risk behaviour among men who have sex with men and transgender women in Lima, Peru. BMC Public Health. 2015; 15(1): 1-8. doi: 10.1186/s12889-015-1730-5

31. Equality and Human Rights Commission. Technical note: Measuring gender identity. 2012. 